\title{
The Information Characteristics and Controls in E-Commerce
}

\author{
Yong Liul, Junping Qiu2 \\ 1 Information Science Department, Zhengzhou Institute of Aeronautical \\ Industry Management, Zhengzhou, P. R. China, \\ y_liu@zzia.edu.cn \\ 2 Research Center for Chinese Science Evaluation, Wuhan University, \\ Wuhan, P.R.China
}

\begin{abstract}
The paper points out the significance of information control at first and then arises some Characters of information in e-commerce. Further more, the author analyzes the concept and ways of information integration and information flow control.
\end{abstract}

\section{The Inevitability of Information Control}

All commercial activities take information as intermediary; the e-commerce superiority lies in the full use of the commercial function of information network, further strengthened the information intermediary function. Depends upon this function, we may promote enterprise's management level and reduce the running expenses greatly, orient the goal market quickly, more strive for and maintain the customer relations, achieve the goal of improving efficiency of the commercial activity. The success rate of the business activity is directly correlated with symmetry of information exchange.

The information exchange of the traditional commercial activity takes hard carrier of information as the core, such as paper carriers, magnetism carriers, optics carriers, practicality carriers, communication establishment, terminal unit and vehicle, etc. These carriers have a lot of limitation in information exchange, such as time, space, region, specialty and personnel. But e-commerce is different, information carrier which appears with high-efficient information transport apparatus with the information network for main fact, not only has avoided all sorts of restrictions of information exchange but also opened up the information exchange channel greatly. In e-commerce era, information value among commercial activity is more prominent than any time ${ }^{[1,2]}$. Meanwhile, because of the e-commerce information characteristic itself, its management problem will be more complicated. It is essential and urgent to

Please use the following format when citing this chapter:

I.iu, Y., Qiu, J., 2007, in IFIP International Federation for Information Processing, Volume 251, Integration and Innovation Orient to li-Society Volume1, Wang, W. (I:ds), (Boston: Springer), pp. 593-600. 
study information integration and information flow control on the basis of ecommerce.

\section{The Inevitability of Information Control}

Transmitting and processing commercial information by using the Web technology is an important technical feature of e-commerce, but information in e-commerce has own Characteristics.

From the angle of commodity exchange, e-commerce is not the operation transaction activity which completes by the physical exchange or the direct physical contact, but the operation transaction activity between transaction parts by the digital way, which indicated that information in the e-commerce has the digital feature.

From the angle of financial process, e-commerce is the commercial activity that transaction parts take the internet as platform to realize business contact, the data transmission, the commodity exchange, the bank credit payment and the settlement, which indicated that information in the e-commerce, has the integrated feature and collaboration or coordination feature.

From the angle of the operation pattern, e-commerce is the commercial activity that using modern information technology to change the traditional commerce pattern, which implied information in the e-commerce, has the control feature.

From the angle of technical application, e-commerce is the process that includes internet, digital information and commerce activity. In brief, e-commerce is informanization of commerce. In other words, the essence of e-commerce is the trade without paper, which means that there is massive information flow to process in the e-commerce activity, but logistics, the fund flow and other commercial factors must also process and transform as the form of information flow. One of e-commerce goals is the realization of complete alternation of entire commerce information, in order to gain more attachments value and the profit. This indicated that information in the ecommerce has the economical increment characteristics.

The development of network technology impelled the appearance and the development of e-commerce, and e-commerce through the information interaction affects information technology and value orientation of the social consumption behavior, which indicates information in the e-commerce has guiding feature.

Through the analysis above, information Characteristics in the e-commerce are extremely obvious, namely the information in the e-commerce has digital feature, the integration, the coordination, the controllability, the increment and the guidance feature and so on. In addition, the information in e-commerce also has the specialization, pertinence, large in quantity, the globality, the direct link, effectiveness, independence, openness, the interaction, sharing, inexpensive, authenticity, normative feature. ${ }^{[5,6,7]}$ and so on.

\section{Information Integration Control}




\subsection{Conception of information integration}

As a technical methodology, Information Integration puts the information resources of e-commerce related application systems into the uniform information system architecture, thus realizes the division of work, cooperation, united management and effective utilization of information according to predetermined target. Information Integration does not mean simply gathering the information of related application systems, but mean integration based on technology, including the integration of application system interfaces, integration of information resource controlling agents, integration of organization and management model, integration of information users and services ${ }^{[3]}$, etc. The core of Information integration is to merge information resources using modern information technology, and to realize the organic combination of information, technology, and intelligence, so that information resources can be well shared and effectively utilized.

The information integration of Enterprise Resource Planning and e-commerce technology is an effectual way for e-commerce information integration control, so it is focused and discussed in detail subsequently.

\subsection{Information integration control}

Two information chains exist in an enterprise: supply information chain, and market information chain. Thus, there are two separate application systems, namely Supply Chain Management system and Customer Relation Management system. ERP works as whole to link these two chains. The information exchanging relationship of them is displayed below as figure 1 .

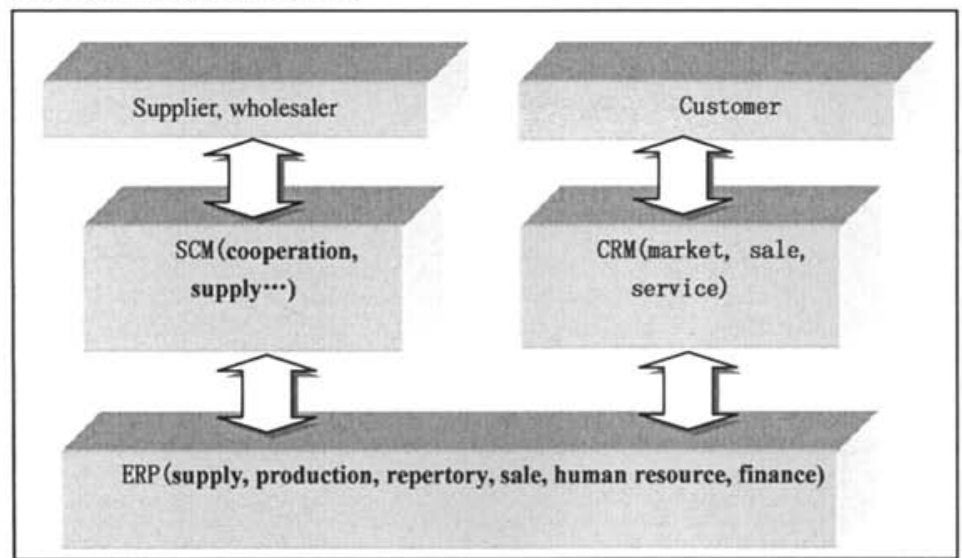

- Fig. 1. An AND/OR-network $\mathrm{N}$ on the left and a realization of $\mathrm{N}$ on the right side. ANDnodes are drawn as circles and OR-nodes as shaded squares

A unified information platform is essential for information integration control, which integrating independent application systems through network and e-commerce, and covering all the flows from suppliers to customers, to establish a unified ecommerce information integrating architecture. It's displayed as chart 2. 


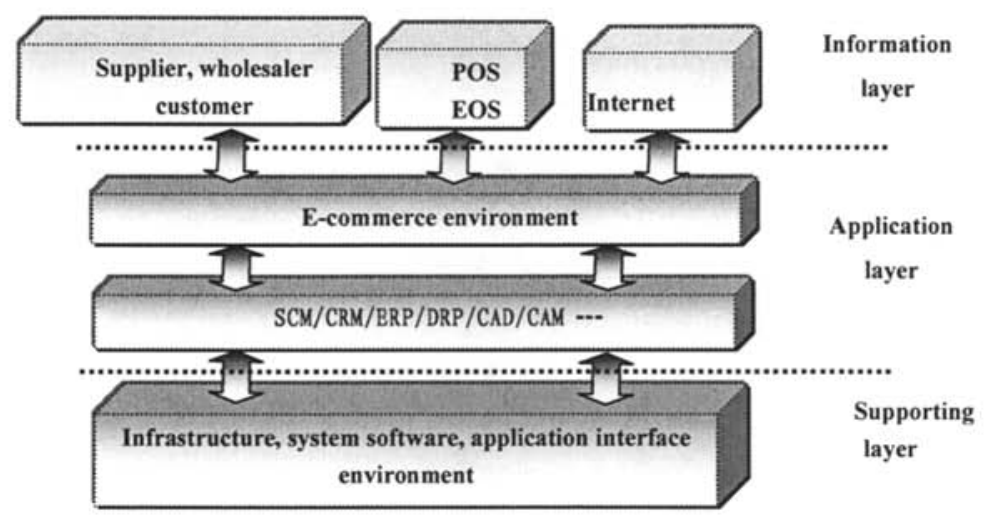

- Fig. 2. E-Commerce Information Integration Architecture.

The environmental structure of e-commerce information integration control is divided into three layers: supporting layer, application layer, and information layer. The e-commerce environment has integrated Web, EDI(Electronic Data Interchange), $\mathrm{CA}$ (Certificate authority) technology, etc., and provides interface for SCM(Supply Chain Management), CRM(Customer Relationship Management), ERP(Enterprise Resource Planning), DRP(Distribution Resource Planning), CAD(Computer Aided Design), CAM(Computer Aided Manufacturing) applications, so it plays a key part to build a information exchange channel.

In the information environment level, the real-time connection between POS (Point Of Sells) and EOS (Electronic Ordering System) provided by the e-commerce environment makes the commodity sale information to be read straightly. The way of online ordering work and exchanging the order information is using the communication network and the computer system transmission.

The integration between the e-commerce and the enterprise application system such as ERP, CRM and SCM will promote information communication between the supply chain and the customer chain, enhance the supply chain efficiency, satisfy the needs of the enterprise multiplication manufacture and the individuality service, effectively operate the interior and exterior enterprise resources, enhance customer satisfaction, meets the global competition and provides the source power which the enterprises develop.

With the further development of e-commerce technology, the information integration control construction transforms from the core with ERP, SCM and CRM to the core with synthesis information integration between content management, knowledge management and data warehouse, which will realize the more widespread information integration control.

Information integration control based on e-commerce will be the important way of future commerce development, which can avoid the unidirectional of the supply chain and customer chain information transmission in the traditional commerce pattern, effectively carry on the information track, the information record, the information storage, the information transmission, the information analysis and the policy-making consultation using the commercial network. Which will improve 
business management pattern, reduce the enterprise operation cost and the merchandise stock cost, fully use all kinds of resources, multi-way develop personalized products and open the customization service. It is important for enhancing the enterprise goodwill, improving the customer relations, enhancing enterprise's core competitive ability or executable ability, and finally obtaining sustainable development ability.

\section{Information Flow Control in e-Commerce}

The e-commerce information flow control is the establishment carries on in the information integration control foundation, if the information integration control provides is static integration frame, the information flow control then provides the dynamic information management method, belongs to the information collaboration or coordination control category.

\subsection{Information flow in e-commerce}

The traditional commercial activity has the concepts of the fund flows and the material flows, to the information flow had not taken the coordinate concept raises in, the main reason is the commercial information production and its transmission are most contains in the material flows, like the letter wraps mailing, facsimile receiving and dispatching, market information exchanging, transportation commodity information transmission and so on. In these ways, the information flow might be called the real scene information flow, also might become on the spot information flow. In this kind of situation, the obtaining, the processing, the transmitting and the exchanging of commercial information need to consume a mass of material flow.

The establishment in information superhighway foundation, e-commerce causes the information flow to separate itself from the material flow and the commercial flow, so that the information flow had the feature of non-real scene or not on the spot. The people use each kind of communication equipment and the information network carry on the information interactive, thus enable the information flow to have own cost and relatively independently comes out from each kind of commercial essential factor. Information flow independence, not only reduced the cost greatly which the material flows, moreover may provides the increment service for the material flow, the commercial flow, the fund flow and the economical management, this is significant difference between the e-commerce and the traditional commerce.

Is precisely because the Characteristics of independence and openness of information flow in e-commerce, in addition as mentioned earlier the Characteristics of digit, integration, the collaboration or coordination, the controllability, the increment and influence function of information and so on, the forming, obtaining, processing, the transmitting and the utilizing of e-commerce information then has many new problems, such as false information and information security questions ${ }^{[4]}$. Therefore, it is necessary to arise the information flow control concept and reasonable method through the effective way, by guaranteed the e-commerce activity with security and reliability while carries on the e-commerce construction. 


\subsection{E-Commerce information flow control method}

The information flow control method is the core of information flow control. In the e-commerce system, the information has its own operators, such as producer, disseminators, consumers, managers and so on; therefore the information flow control also divides into subject oriented control method and the object oriented control method.

The information flow subject oriented control divides into five kinds of types as below: the producer control, the issue control, the disseminator controls, the consumer control and the manager control. The object attributes and the control method have the difference respectively, but have many same places included the information flow object oriented control. Summarizes, has the following several controls method:

\subsubsection{E-Commerce information flow control method}

The technical control is essential method for the e-commerce information flow control, which mainly solves the questions of order and security nature for the ecommerce information flow. At present, the e-commerce information technical control research are quite many, mainly includes the technical standard and the standard control, the control system and the management system control, the gateway website control, the firewall technical control, the data encryption technical control, the digital signature technical control, the digital time stamp technical control, the digital certificate control, the identification authentication and the access control, the information divulges protection technology, the e-commerce certification authorization organization transaction authentication control (CA, Certificate Authority), Internet's security agreement control etc.

The e-commerce information flow technical control belonging to the microscopic control is not the only useful means of information flow control, and could not solve all the problems. Therefore, we have to consider other complementary methods.

\subsubsection{Policy method}

The country and the government affairs have the macroeconomic regulation and control function to the e-commerce, through the management information, the economic information and the commercial information standard, overcomes the limitation of technical control, and solves the problems which the microscopic information control is not easy to solve.

Generally speaking, the country and the government have two ways to strengthen the macroeconomic regulation and control for e-commerce.

One is from the technology standard control, formulates and promulgates the ecommerce service standard, the data format standard as well as the relevant policies, like the digital signature implementation policy, the intellectual property rights protection policy, the electronic payment policy and so on, to play role of information standard and the policy guidance.

Two is macroeconomic regulation and control, like to promulgate the ecommerce tax policy, the financial policy, the credit policy, the service of material flows policy, the trade policy and the human resources policy and so on, in order to 
establish the e-commerce information safeguard system and information flow arrangement function.

\subsubsection{Legal method}

The perfect legal laws and regulations system is the guarantee to develop ecommerce, also is the important condition to control the information flow in the whole. The legal method may to supervise the e-commerce participant's information behavior and to restrict information source and transmission flow. Is same with the traditional commercial activity, the legal laws and regulations can maintain the ecommerce activity in the course of nature normally and protect legitimate benefit among all participates in the e-commerce.

\subsubsection{Humanities method}

Moral method, public opinion method and education method, all above methods belong to humanities method which may adjust human's information behavior, makes up flaw of the economical and technical management in the way of e-commerce, so to achieve the purpose that to strengthens the information flow reasonable use and the efficient management.

\subsection{E-Commerce information synergetic control}

The information synergetic control is the synthesis utilizes each information control method, forms the coupling the control system, and builds the harmonious ecommerce information environment. The way of information synergetic control may have the three ways as below:

\subsubsection{Organization synergetic control}

The function is to harmonize as well as adjust the business relations among each kind of organization or to establish unified e-commerce management organizations and agencies, like the establishment e-commerce information association and so on. We can then entrust them with the certain information control jurisdiction, in order to form the perfect organization and manage system which can synthesize utilizes each information control approaches to strengthen concentrated surveillance and control relate to the information flow.

\subsubsection{Service synergetic control}

The establishment of integrated e-commerce information service network will turn commercial information supply to integrated information supply. Meanwhile, through standardized the information integration service system, we can meet commerce information requirement for customers. 


\subsubsection{Operation synergetic control}

All information flow control means and the methods must be performed through practical work by the operation layer. The synergetic of operation layer can influence the overall effect result from synthesis application of information control method directly. The operation synergetic involves several aspects like the e-commerce onstage website information management, backstage material flow information management and the intermediary information system. The information synergetic control plan in each aspect may be alone designed.

\section{Acknowledgments}

This article is supported by National Natural Science Foundation of China (Item No.70673071).

\section{References}

1. F. Kleist, "An Approach to Evaluating E-Commerce Information Systems Projects". Information Systems Frontiers, Vol.5, No.3, 249-263(2003).

2. I. Lewis and A. Talayevsky, "Improving the interorganizational supply chain through optimization of information flows". Journal of Enterprise Information Management, Vol. 8, 229-237(2004).

3. P. Finnegal, "Systems Planning in Business-to-Business e-commerce Environments". Information Technology and Management, Vol.4, 183-198(2003).

4. S. Rohrig, "Security Analysis of Electronic Business Processes", e-commerce Research, Vol.4, 59-81(2004)

5. Y. Mao, "Information Flow in e-commerce", Information Science, Vol.6, 626-629(2002).

6. Y. Liu and W. Z. Yang, "The Developing of Cyberspace and Controlling of Information Flow", Archival Management, Vol.3, 4-5 (2003).

7. X. C. Lou and A. Z. Zhang, "Information integrated analysis process", Information Theory and Application, Vol.2, 101-104(2002). 